\title{
ARTICLE
}

\section{A pilot geomagnetic and magnetotelluric survey in Mogod area of the Eastern Hangai, Mongolia}

\author{
Batmagnai E. ${ }^{1,2} *$, Tsegmed B. ${ }^{1}$, Nasan-Ochir T. ${ }^{1}$, Gantsogt S. ${ }^{1}$ and Eldew-Ochir B. ${ }^{1}$ \\ ${ }^{I}$ Insitute of Astronomy and Geophysics, Mongolian Academy of Sciences \\ Ulaanbaatar, Mongolia \\ ${ }^{2}$ Institute of Geophysics, ETH Zurich, Switzerland
}

\begin{abstract}
The paper are the preliminary results of the study of the hydrothermal system of Khulj, which is located in Mogod soum of Bulgan aimag, carried out using magnetotelluric and magnetic methods. Khulj's hydrothermal system is an interesting geodynamic structure located in the area of a young volcanic mountain in the eastern part of the Khangai Mountains. The study was carried out using two geophysical methods. The first is the magnetotelluric measurement, which registered variations of 3 components of magnetic field (Bx, By, Bz), and 2 components of electric field (Ex, Ey). In addition, we have provided a total of 8 magnetic field profiles for an area of $4 \times 8 \mathrm{~km}$. The sample rate of the total magnetic field was 3 seconds, which corresponds to about 3 meters. The programme's codes are written in $C++$ and Matlab and the result of this code is a programme called INV2DMAG. This programme is based on the inversion method of the Levenberq-Marquardt algorithm. Magnetotelluric results show that one-dimensional models clearly display the depth, the thickness of precipitation, as well as the thickness of the Moho boundaries. A preliminary two-dimensional magnetic structure, determined from small-length profiles, provides very useful insight into understanding the shallow deep structure of the sedimentary soil of the region in and around Mogod. In the Mogod's hydrothermal system, we expect that the hot fluid heats up from granites, which have a deep source. For a detailed research, repeat field measurement is required to determine not only the structure of this geothermal system but also to determine the depth of the sedimentary soil.
\end{abstract}

Keywords: Magnetotelluric sounding; geomagnetic field; inversion method; geothermal system;

\section{INTRODUCTION}

The Khangai Mountain ranges in central Mongolia are an intra-continental mountain range ( $2 \mathrm{~km}$ above sea level) stretching from the Siberian and the Indo-Asian tectonic plate margins. Geological history of the existence of numerous hot springs in and around the Khangai Mountains is indicative of a large hydrothermal system, and the hot springs are remnants of its volcanic geology history, which are the results of mantle-driven uplift from beneath the Khangai Mountains [1, 2, 3, 5]. One of the quite interesting hydrothermal systems in the eastern part of Khangai is the Khulj hot spring on the territory of Mogod 
soum, Bulgan aimag. An earthquake with a magnitude of M7 struck the region on 5 January 1967, which became one of the strongest seismic movements in modern Mongolia.

Early geological, geochemical, and geophysical surveys conducted in the Mogod's seismic active region had determined the geological conditions and had presented the seismicity of this region. Since 2016, magnetotelluric studies have been carried out in the central part of Mongolia, especially in the Khangai Mountain area, and some unexpected results have been obtained related to the geodynamic process of the Khangai Mountain ranges.

Magnetotelluric survey could determine deep conductivity mechanism around the Khangai plateau $[3,5]$, but it did not include the eastern part of mountain ranges. In the recent times, comprehensive geophysical surveys were successfully carried out in the Mogod seismic area [1, 2], but it only focused on the shallow depth of the Earth layers (about $50 \mathrm{~m}$ ). Unfortunately, it could not determine or identify any source effect such as geodynamic and geotectonic evolutions. Hence, we need to conduct another geophysical study in the area.

This study primarily focused on the development of geo-electromagnetic methods in Mongolia for investigating the Earth's deep structure. We measured magnetic profiles and magnetotelluric sites, which is the first step in our study to understand mantle-driven uplifting beneath the eastern part of the Khangai Mountain ranges.

The geo-electromagnetic methods can probe the Earth's structure as deep as around $1600 \mathrm{~km}$ to determine conductivity variation, distribution of magnetic materials, partial melting, and the composition of the Earth materials. In future we are planning to conduct large-scale magnetotelluric (MT) and geomagnetic measurements in the Mogod and Tüleet fault regions, the purpose of which is to determine the geo-electromagnetic structure in the area surrounding Mogod. Of greater interest is the fact that the Khulj hot spring is located at the very centre of Mogod soum, which is indicates that it lies in the geotectonic activity zone.

In this respect, our study is very important for a better understanding of geothermal mechanism and geomechanics procedure. Another important reason which this study has been carried out is that it aimed to develop inversion code for the MT and magnetic data sets. Modelling the Earth's subsurface and explaining the physics mechanism inside the earth are important.

In this study, we have consider the development and the study of modelling methods in the context of $1 \mathrm{D}$ MT and 2D magnetic inversion. Using field data for the code test, a number of practical aspects related to implementation of inversion code have been covered here. General formalism, which is mentioned in this work about MT was adopted from a formulation presented by Batmagnai, E. et al (2018). To the author's knowledge, this is the first study of its kind that implements and demonstrates all these techniques in the context of earth's deep electromagnetic imaging.

\section{RESULTS}

\section{Field settings}

In recent studies, most of their authors have concluded that the far field effect of the Indo-Asia collision is the main factor driving mountain growth in Mongolia [9, 10]. The most prominent of the Mongolian mountains is the Khangai Mountain range, which is the largest chunk of the Mongolian plateau [3, 4, 9]. The Khangai region is covered by sparse Cenozoic and Quaternary basaltic volcanism stretching several hundreds of kilometers [7, $10]$.

The basement geology of the Khangai Mountains is an old Precambrian that contains 
tonalitic and potassic granitoids, and is overlain by thick Paleozoic turbidities. Surface geology of the mountain range is similar to that of the surrounding regions with Paleozoic sediments and is volcanic with intrusive granitoids. Only a few short normal faults have been found (Bayanbulag valley, Shilüüstei, Egiindavaa, etc.) in and around the Khangai Mountains $[3,5]$ where the topography is the highest, whereas several large E-W strike-slip and reverse faults were active on both sides of the mountain ranges during the last century $[4,5$, $6]$.

In the Mogod region the earthquake source, reaching the surface in the form of an extended system of faults, encompasses the N-S and NW-SE planes of two large faults near the juncture zone. Another interesting feature of this region is the spring (Saikhan Khulj) created as a result of neotectonic uplifting of Cenozoic in the Orkhon River valley. Most Cenozoic volcanos are located in the eastern part of the Khangai Mountains where the hydro-geothermal system in one of the best in terms of quality of the fluid heat-carrier with a high yield of thermal source as it is situation in an area of deep magma chamber and high Cenozoic volcanic activity (Fig. 1).

In a pilot magnetic survey near Saikhan Khulj hot springs, we measured 8 profiles and, in the pilot MT survey near the Mogod fault, we measured 3 MT points. The MT points were installed near the trench.

\section{Magnetic survey}

In June 2018, magnetic data were acquired at 8 profiles in a area of $4 \mathrm{~km} 6 \mathrm{~km}$ in Mogod soum, which included also the Khulj hot spring (Fig. 1). An Overhauser magnetometer from Russia was used for magnetic profile measurement. Only the total intensity of the geomagnetic field was measured, and where the profiles were oriented from north to south, they were measured to parallel with the Mogod fault.
Magnetometer and Global Positioning System (GPS) data were collected simultaneously at $3 \mathrm{sec}$ intervals. The height of magnetometer above the surface was about $1.2 \mathrm{~m}$. A reference magnetic station was installed for carrying out magnetic survey, which is crucial for rectifying geomagnetic variation generated in the ionosphere and magnetosphere. Most of the profiles are less than $1 \mathrm{~km}$ from the centre of Mogod with a population of less than 2,000 and there is. galvanic noise from electric cables and telephone poles in the village.

In addition, the ground magnetic data were corrected for diurnal variations of the Earth's magnetic field using base-station magnetometer, a regional International Geomagnetic Reference Field (IGRF-12) appropriate for the time of the survey, and single data outliers greater than $150 \mathrm{nT}$. The data is presented in Fig. 2. We used reducedto-the-pole (RTP) method for geomagnetic correction analysis (Fig. 2).

We have developed magnetic 2D inversion code by implementing the $\mathrm{C}++$ and Matlab, which is so-called INV2DMAG. The INV2DMAG is used for inverting the corrected magnetic profile data. In future, we can use that code extensively in the magnetic survey.

This code is based on the underdetermined inversion problem [8], thus we used real data, which we measured for the forwarding solusion.

The initial guess or starting model is a uniform magnetic susceptibility distributed in each cell. Here the cells depend on the measurement of the length and density of the profile. Inversion process of INV2DMAG is a gradient-based inversion algorithm, which is Levenberq-Marquardt algorithm. One major advantage of directly performing the 2D inversion is that there is no need to conduct regional field correction. 


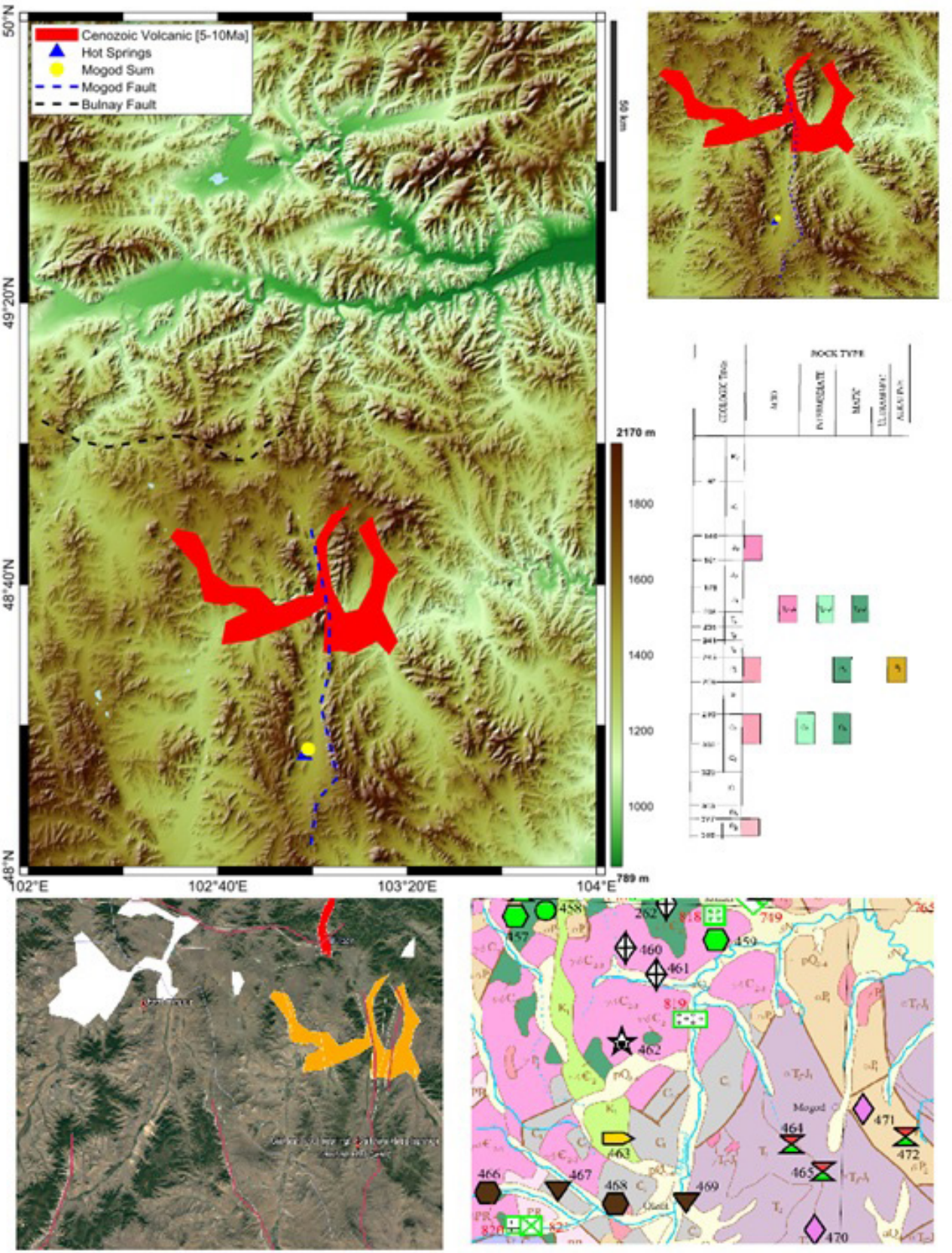

Figure 1. Information of field area, the polygon which marked red color (orange color) shows Cenozoic basalts around $5-10 \mathrm{Ma}$, in upper left side plot shown elevation of our interested study area where yellow dot is center og Mogod sum, blue triangle is hot springs reached surface, dashed blue line is Mogod fault, and the black dashed line is Bulnay fault. Other maps contain dashed blue 

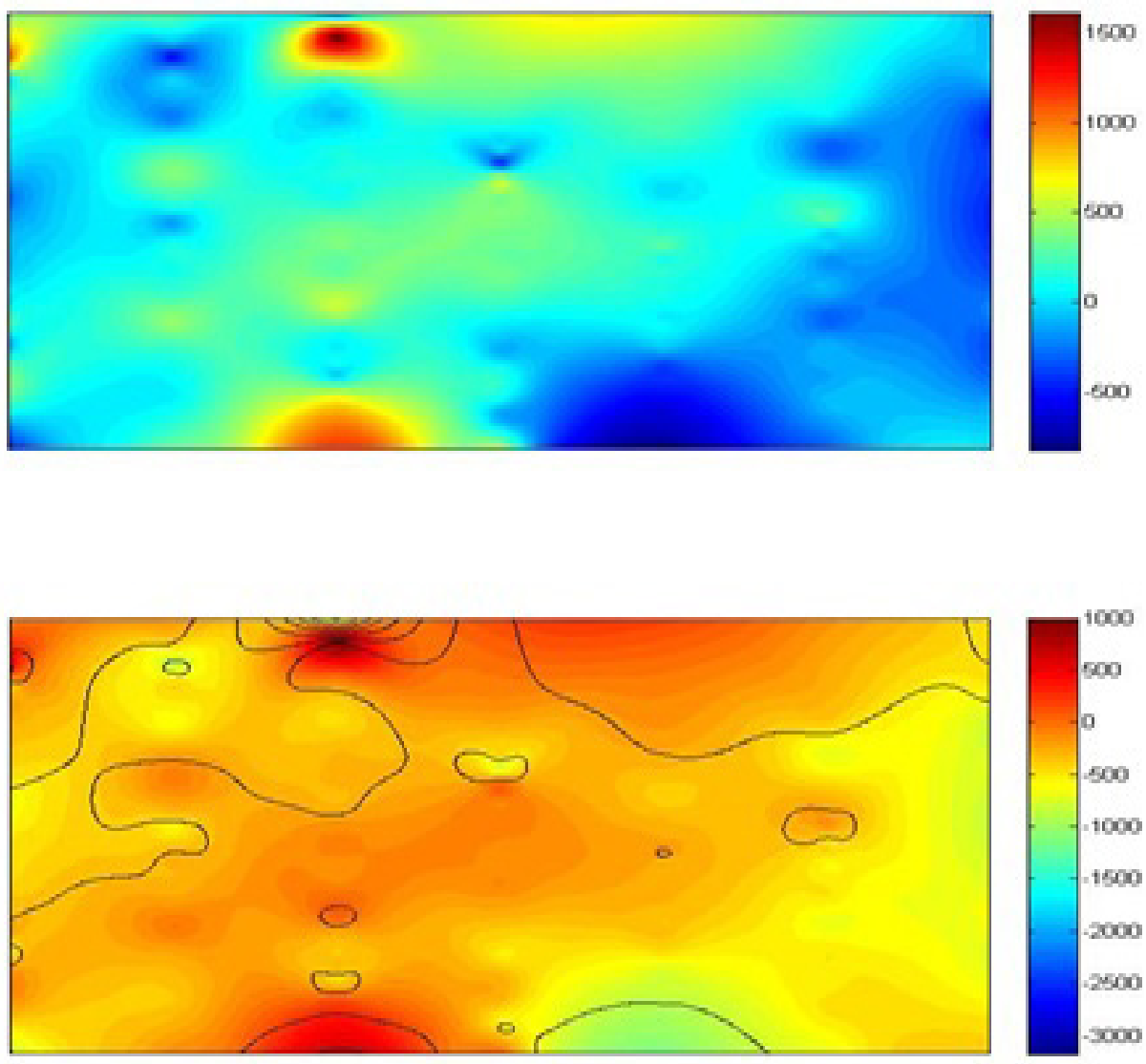

Figure 2. Total magnetic intensity map, upper plot shows the observed data where the main field and magnetic variation fields remived, down plot shows the corrected results from the Reduced to the pole method

We inverted real data from initial guess model to the best-fitted model. After inversion, which runs multiple times with different initial model's parameters, the distribution of magnetic susceptibility was obtained. The preferred inversion result was obtained by using a $\chi=10 \mathrm{e}-3$ for each cell and it was found that there was a difference of about 10.2 in the observed and estimated response in the initial model to produce the normalised RMS. After 8 iterations, the misfit level decreased to about 1.3 RMS (Fig. 3). Three main features are shown in Fig. 3, which may be associated with metamorphic rocks that are uplifted by volcanic and seismic interference. Fig. 3 shows a 2D modeling profile, which was measured right at the Mogod fault. 


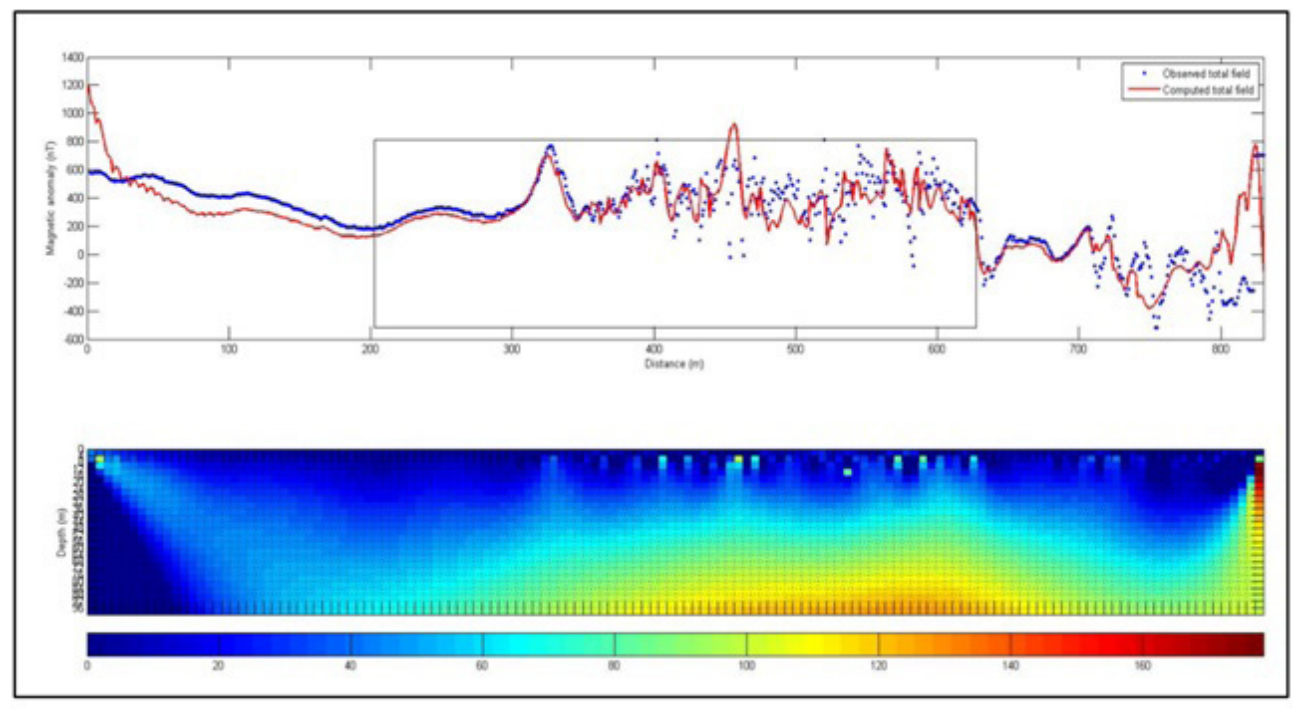

Figure 3. Inversion results of the sample profile, in the top, plotted fitting of the real data and our modelled data. In the bottom, 2-D distribution of the Earth's magnetic susceptibility, where $Y$-axis sounding depth, to determine from surface to $100 \mathrm{~m}$, $X$-axis length of the line

\section{Magnetotelluric survey}

We have measured the time variation of the geomagnetic and electric fields, which is called magnetotelluric (MT) survey. The MT method is a very powerful technique for imaging conductivity of the subsurface. The objective of a pilot MT survey was developed for applied geophysics, which contributed to an increased resolution of sounding depth as the geophysical survey was conducted deeper. MT data were acquired at three sites in the Mogod region, which included the youngest fault that had taken shape in 1967 [5]. All sites used search-coil magnetometer Lemi-30 from L'viv, Ukraine and EDE-032 data loggers and electrodes from Munster, Germany. Only the components of the electric field $(E x, E y)$ were measured with reference magnetic station, where $\mathrm{x}$ is oriented north and $\mathrm{y}$ is oriented east. The electrodes (AgAl), broadband magnetic coils (Lemi-120) and acquisition units were left overnight for a total of about 72 hours at each station (at $250 \mathrm{~Hz}$ sampling rate) to acquire the data. Most sites are located more than $10 \mathrm{~km}$ from Mogod soum, thus the influence of the human settlement was not recorded in the data (Fig. 4). Time series processing and transfer function estimation were then done with the Matlab processing code developed by E. Batmagnai [1, 2, 3] based on the Michael Becken main functions. It employs a cascading decimation scheme with eight levels, where each level reduces the sampling frequency of the time series by a factor of four compared to the previous level. Thus, the sampling frequency of the last decimation level is reduced by a factor of. The decimated time series were cut into windows with a length of 128 samples and an overlap of 32 samples. Each window (Hanning window) is tapered and Fourier transformed.

In the frequency domain, instrument response was removed and the spectra were divided in intervals with a width of about half an octave and with a central frequency of . All Fourier coefficients within the same frequency interval across all spectra of certain decimation level were then used to estimate transfer function of its central frequency. Least-square regression is biased by non-Gaussian noise when the M-estimate robust processing is used. A variation along the line of apparent resistivity at 3 stations is shown in Fig. 4. 


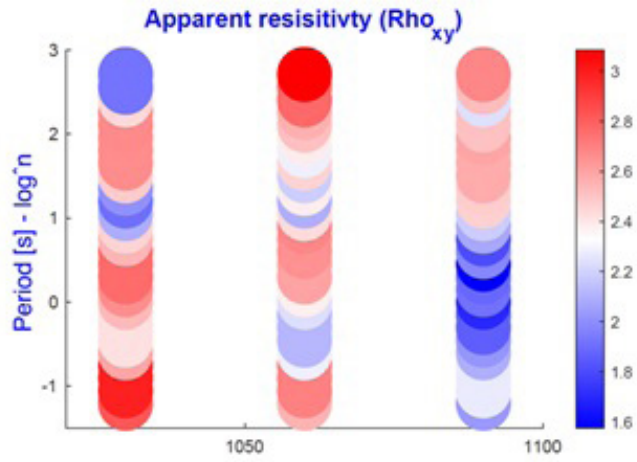

Figure 4. Sounding Curves, shows pseudo plot along profile which is shows variation of the apparent resistivity period dependence in all three stations

We obtained some useful signal in the range of 0.001 to $64 \mathrm{~Hz}$ from a pilot survey of MT. The regionally averaged impedance can be used as the input for inversion. Therefore, SSQ - impedances were calculated in the frequency range between $64 \mathrm{~Hz}$ and $1000 \mathrm{~s}$ for every station and then averaged over each three stations, resulting in 27 data points for

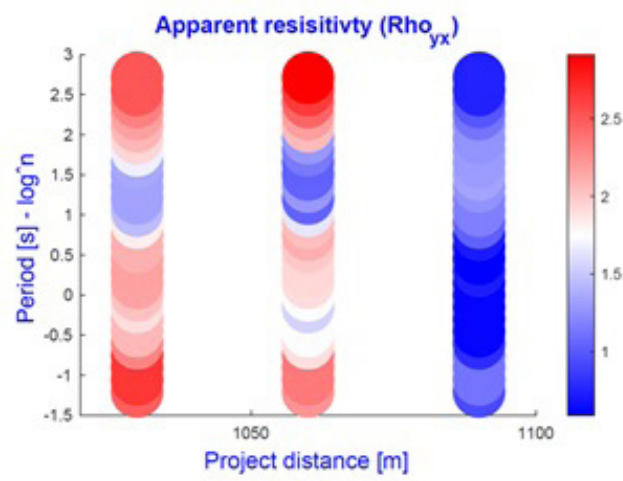

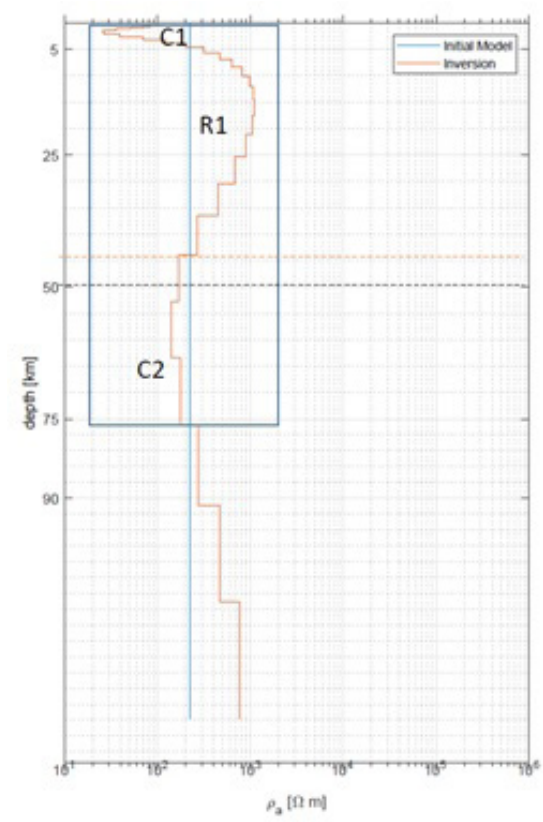

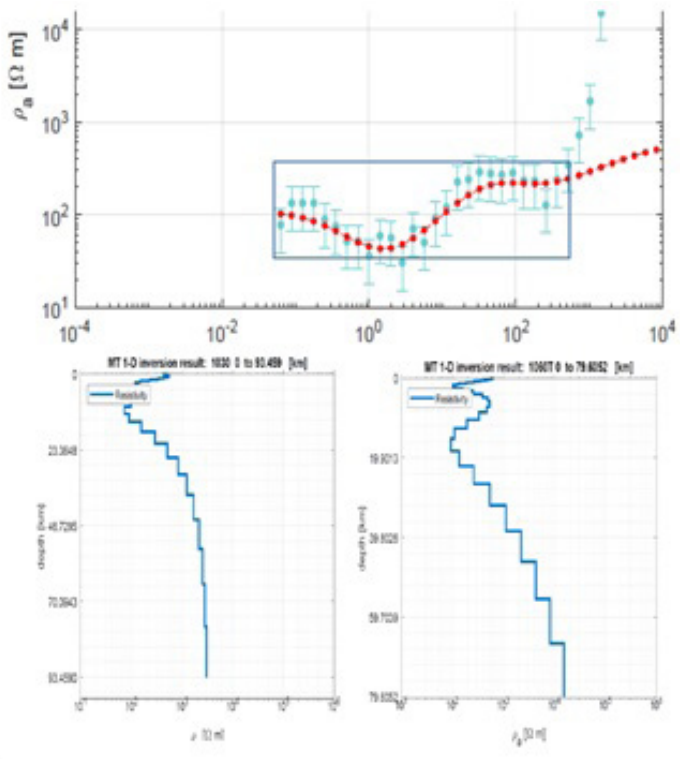

Figure 5. 1-D inversion results for the three points, in the left column, the best-fit model (orange), the initial model (blue line) are plotted. The right column shows the data fit of apparent resistivity and the best-fit model in the other ponts 
The inversion was performed using the Gauss-Newton algorithm. The L1.5 is a norm for regularisation to achieve a smooth model with low misfit.

The three points have very similar results in terms of conductivity structure. There is a shallow conductivity layer demonstrated at 500 to $2000 \mathrm{~m}$. At a depth of $25 \mathrm{~km}$, the conductivity increased to maximum with an underlying resistive layer at 60-70 km (Fig. 6).

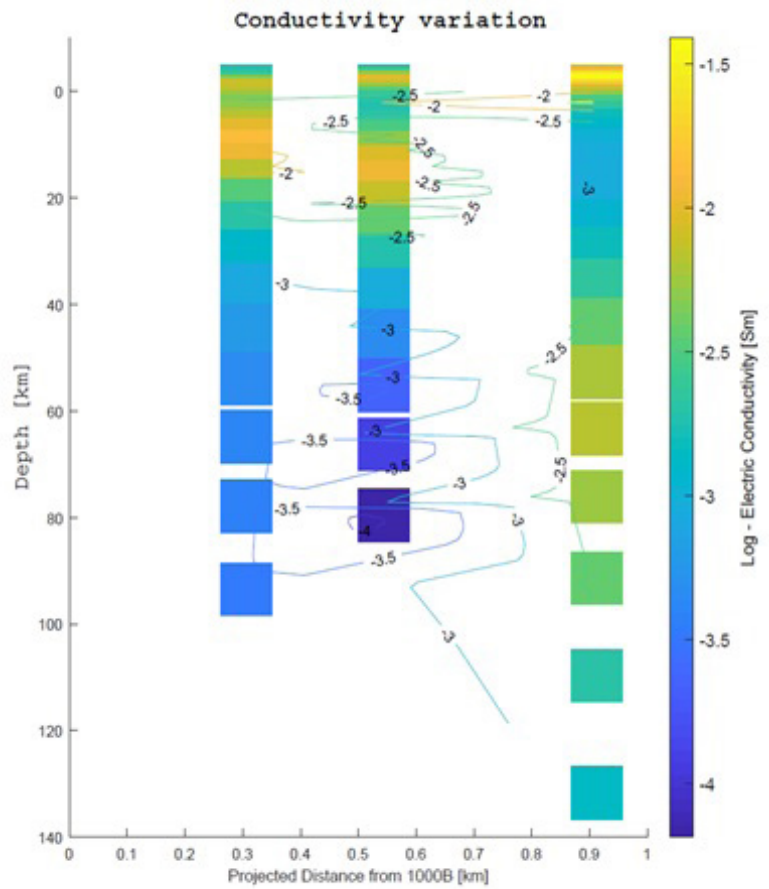

Figure 6. Conductuvuty variation for the line with three points

\section{DISCUSSION}

The previous section shows that the inverted MT and Magnetic models contain a few prominent features from magnetic data. In this section, we link these prominent features with the geology of the area.

The high magnetisation zone $\mathrm{Cl}$ is close to the hot springs and the Mogod fault (indicated by A1, A2, in Fig. 5) but it may be separated into two zones of $70 \mathrm{~m}$ in depth provided the measured data have enough length. Since there is a correlation between the hot springs and the magnetisation beneath, we can, therefore, suggest that A1, A2, and
C1 are uplifts for the faults. According to prior geological information (Fig. 1) and the surface geological map, the non-magnetic case corresponds to Triassic granite and Quaternary sedimentary. Thus we can suggest the depth of the sedimentary basin corresponding to nonmagnetic section is $20-50 \mathrm{~m}$ along such as profile.

From the magnetotelluric data, we can find the resistivity contrast between the conductivity features $\mathrm{C} 1$ and $\mathrm{C} 2$ (Fig. 5, 6) in our inverted model. The contrast R (Fig. $5,6)$ can be interpreted as the Precambrian 
continental block overlain by Paleozoic turbidities. Our inverted model is very close to the fault rupture on the ground. Hence, $\mathrm{C} 1$ conductor is the product of the fault effects.

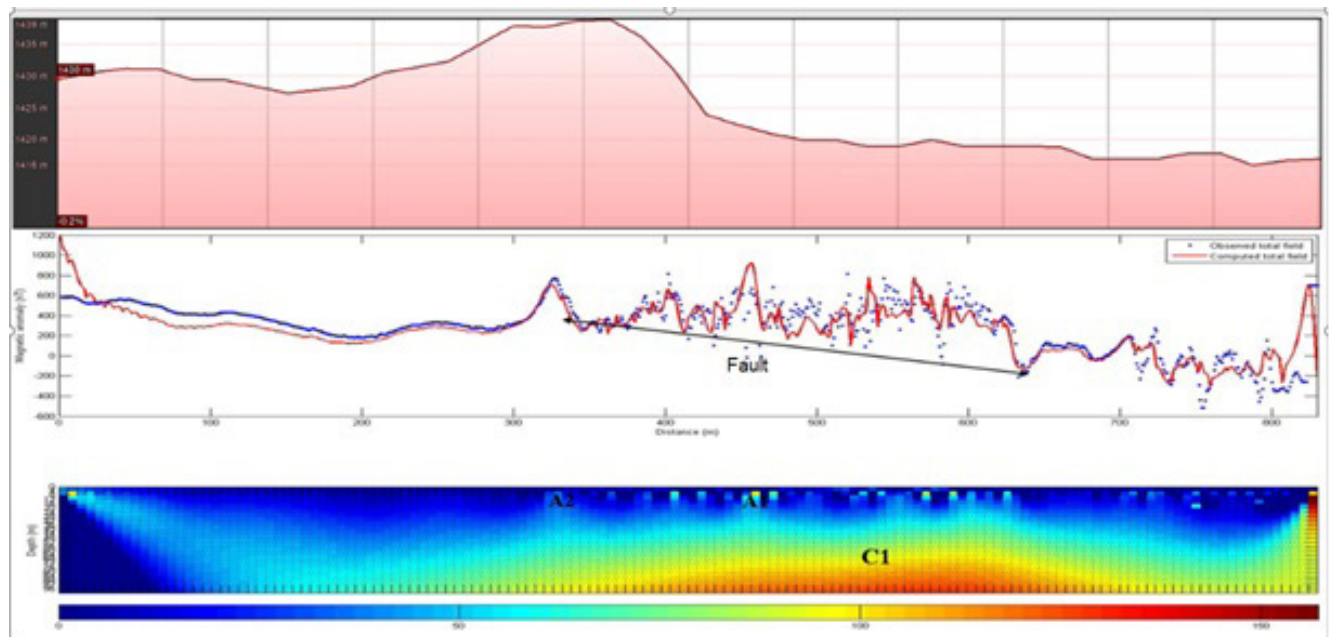

Figure 7. Inverted magnetic data: upper plot is shown on elevation, middle plot shown on observed and calculated data, and down plot shown on the result of inversion where we marked A1, A2, and C1 prominent features

This study helps confirm of the fact that the inversion code development for magnetic and MT data processing is available for future use because the data fitting between the calculated and observed responses is good and the results of the inverted model, which are MT 1D electric conductivity and 2-D distribution of magnetic susceptibility, coincided with surface and structural geology conditions. We
From our one-dimensional inverted model we can identify the conductor of upper mantle $\mathrm{C} 2$ and the Moho depth. 
band effects and local distortion from MT sounding curves. In the future, we are making a plan to study large scale MT and magnetism in the eastern part the Khangai Mountains, where a few Cenozoic volcanos are located. Thus it's a very interesting location for the heat flow and geodynamic studies.

\section{CONCLUSIONS}

A 2D preliminary magnetic structure determined from small length profiles covering the Mogod soum provides very useful information on assessing and understanding the shallow structure of the Mogod area. In the Mogod hydrothermal system, we expect hot fluid heated from the deeper granites, identified as high resistivity feature R1 (Fig. 5). A fracture in the damaged zone of the fault (shown as a high magnetisation in Fig. 3) allows the pressurised hot fluid to reach the surface. But, it is difficult to explain deep source mechanism from where we used data, because our measured data are not sensitive to the deepest source effects. Satisfactory results were obtained for 1D MT model in which sedimentary thickness and Moho depth were properly imaged starting from a very poor initial model. The presented results were found to be in a agreement with similar approaches from other applications of inversion.

Although this work has covered multiple important and novel aspects in Mongolia, there is a potential to further improvement. For instance, other criteria for initial starting steps, which reduce dependence on initial models. More theoretical work is therefore needed in the future. Application of the codes to the real data from the pilot survey was certainly serve as a good check for the methods already developed.

For a detailed research, repeat field measurement is required to determine not only the structure of this geothermal system, but also the the depth of the sedimentary soil as well.

Acknowledgement. Authors wish to thank the Learned Secretary of the IAG MAS Dr. Ch. Odonbaatar for supporting the field works. An anonymous reviewer helped improve the quality of the manuscript. This work is financed under the grant ShUSS-2017/65 of the Ministry of Education, Science, Culture and Sports of Mongolia.

\section{REFERENCES}

1 Batmagnai, E., Sükhbaatar, U., (2016). The magnetotelluric method of signal processing, Journal of Khürel Togoot.

2 Batmagnai, E., Sükhbaatar, U., (2017). Data processing of the LEMI-418 magnetotelluric instruments in the MAG-MTT observatory: from time series to impedance tensor, Geophysics \& Astronomy, 4, pp. 84-92.

3 Batmagnai, E., (2018). Data processing of the Magnetotellurics method, Ulaanbaatar State University, Master's thesis.

4 Bayasgalan, A., Jackson, J., Ritz, J. F., Carretier, S., (1999). Field examples of strike-slip fault termination in Mongolia and their tectonic significance, Tectonics 18, pp. 394-411.

5 Baljinnyam, I., Borisov, B. A., Bayasgalan, A., Cisternas, A., Dem'yanovich, M. G., Ganbaatar, L., Kochetkov, V. M., Kurushin, R. A., Molnar, P., Philip, H., Vashchilov, Y. Y., (1993). Ruptures of major earthquakes and active deformation in Mongolia and its surroundings, Geol. Soc. Am. Mem. 181 pp. $1-59$.

6 Bayasgalan, A., Jackson, J., Ritz, J. F., Carretier, S., (1999). 'Forebergs', Lower structures, and the development of large intra-continental strike-slip faults: The Gurvan Bogd fault system in Mongolia, J. Struct. Geol. 21 (1999). pp.1285-1302. 
7 Bhattacahryya, B. K., (1964). Magnetic anomalies due to prism-shaped bodies with arbitrary polarization, Geophysics, 29, pp. 517-531.

8 Blakely, R. J., (1996). Potential theory in gravity and magnetic applications, Cambridge University Press, New York, NY.

9 Calais, E., Amarjargal, S., (2000). New constraints on current deformation in Asia from continuous GPS measurements at Ulanbaatar, Mongolia, Geophys. Res. Lett. 27. pp. 1527-1531.

10 Constable, S. C., Parker, R. L., \& Constable, C. G., (1987). Occam's inversion: A practical algorithm for generating smooth models from electromagnetic sounding data. Geophysics, 52, pp. 289-300.

11 Cunningham, W. D., (1998). Lithospheric controls on late Cenozoic construction of the Mongolian Altai, Tectonics 17. pp. 891-902.

12 Ellis, R.G. \& Oldenburg, D. W., (1994). Applied geophysical inversion, Geophys. J. Int, 116, pp. $5-11$.

13 Kopylova, M. G., O'Reilly, S. Y., Genshaft, Y. S., (1995). Thermal state of the lithosphere beneath central Mongolia: evidence from deep-seated xenoliths from the Shavarym-Saram volcanic center in the Tariat depression, Khangai, Mongolia, Lithos 36. pp. 243-255.

14 Last, B. J. \& Kubic, K., (1983). Compact gravity inversion, Geophysics, 48, pp. 713-721.

15 Lelievre, P. G. \& Oldenburg, D. W., (2009). A 3D total magnetisation inversion applicable when significant, complicated remanence is present, Geophysics., 74, 3, L21-L30.

16 Lelievre, P. G., Oldenburg, D. W. \& Williams, N. C., (2009). Integrating geological And geophysical data through advanced constrained inversions, Exploration Geophysics., 40, pp. 334-341.

17 Li, Y. \& Oldenburg, D. W., (1996). 3-D inversion of magnetic data, Geophysics, 61, pp. 394-408.

18 Li, Y. \& Oldenburg, D. W., (2003). Fast inversion of large scale magnetic data using wavelet transform and logarithmic barrier method, Geophys. J. Int., 152, pp. 251-265.

19 Nabighian, M. N., Grauch, V. J. S., Hansen, R. O. LaFehr, T. R., Li, Y., Peirce, J. W., Philips, J. D. \& Ruder, M. E., (2005). The historical development of magnetic method in exploration, Geophysics, 70, pp. 33-61.

20 Pilkington, M., (1997). 3D magnetic imaging using conjugate gradients, Geophysics. 62, pp. 11321142.

21 Sharma, P. V., (1966). Rapid computation of magnetic anomalies and demagnetization effects caused by bodies of arbitrary shape, Pure applied Geophysics., 64, pp. 89-109.

22 Talwani, M., (1965). Computation with the help of computers of magnetic anomalies caused by bodies arbitrary shape, Geophysics, 30, pp. 797-817.

23 Telford, W. M., Geldart, L. P. \& Sheriff, R. E., (1995). Applied Geophysics, Cambridge University Press, New York, NY.

24 Menke, W., (1989). Geophysical Data Analysis: Discrete Inversion Theory, International Geophysical series, Volume 45.

25 Zorin, Y. A., (1999). Geodynamics of the western part of the Mongolia-Okhotsk collisional belt, TransBaikal region (Russia) and Mongolia, Tectonophysics 306. pp. 33-56. 